\title{
Takayasu's Arteritis with Renovascular Damage: A Case Report
}

\author{
Ilkhamdzhan Karimdzhanov*, Dilorom Atayeva Rakhimjanovna, Alovkhon Suleymanov, \\ Gulshan Iskanova, Sanjar Egamberdiyev
}

Department of Children’s Diseases, №2 Tashkent Medical Academy, Tashkent, Uzbekistan

Email address:

ilkhamdjan_5346@gmail.com (I. Karimdzhanov), diloratayeva@gmail.com (D. A. Rakhimjanovna), gulshan1972iskanovaa@gmail.com (G. Iskanova)

${ }^{*}$ Corresponding author

\section{To cite this article:}

Ilkhamdzhan Karimdzhanov, Dilorom Atayeva Rakhimjanovna, Alovkhon Suleymanov, Gulshan Iskanova, Sanjar Egamberdiyev. Takayasu's Arteritis with Renovascular Damage: A Case Report. American Journal of Pediatrics. Special Issue: Chronic Kidney Disease in Children. Vol. 6, No. 2, 2020, pp. 152-158. doi: 10.11648/j.ajp.20200602.26

Received: February 19, 2020; Accepted: March 9, 2020; Published: March 31, 2020

\begin{abstract}
Takayasu's arteritis characterizes with severe damage of medium- and large-sized arteries. The pathophysiological progression of full-thickness inflammation of the vessel wall and subsequent fibrosis usually occurs with vascular stenosis and/or occlusion, causing ischemia of the corresponding organs, which is associated with high mortality. the suppression of vascular and systemic inflammation is a major aspect of medical treatment. Glucocorticoids (GC) have been the cornerstone of treatment in TA induction. The remission rate of GC mono-therapy is as high as $60 \%$. However, nearly $80 \%$ of patients develop progressive or alternating (recurrence and remission) forms of TA. The current case report focuses on a Asian middle-aged woman who complained pain in arms, headache, cardiodynia, nausea, edema in lower extremities, low appetite, high blood pressure, loss of physical activity, malaise, and fatigue for as many as 6 years. Deferred diagnosis and lack of specific treatment could explain the severity of the arterial injury at time of hospital admission. Angiography showed multiple narrowing and atherosclerosis of the abdominal and thoracic aorta, unilateral occlusion of the subclavian artery, unilateral occlusion of the common carotid artery, stenosis of the celiac trunk, superior mesenteric artery, bilateral renal arteries, enlarged pulmonary trunk, and unilateral hypoplasia of the left kidney. Early diagnosis and treatment is warranted. Outcome appears to be favorable when the disease is quiescent. Renovascular damage and hypertension is usually resistant to medical therapy and frequently requires complex therapy with invasive management methods, such as angioplasty or surgical bypass.
\end{abstract}

Keywords: Takayasu's Arteritis, Subclavian Artery, Angiography, Multiple Narrowing of the Aorta, Artery Occlusion, Hypoplasia of the Kidney

\section{Introduction}

Takayasu arteritis (TA) is a type of chronic nonspecific large-vessel vasculitis, characterised by granulomatous inflammation in the vessel wall of the aorta and its major branches $[1,2]$. The pathophysiological progression of fullthickness inflammation of the vessel wall and subsequent fibrosis usually occurs with vascular stenosis and/or occlusion, causing ischemia of the corresponding organs, which is associated with high mortality [3, 4]. Therefore, the suppression of vascular and systemic inflammation is a major aspect of medical treatment. Glucocorticoids (GC) have been the cornerstone of treatment in TA induction. The remission rate of GC mono-therapy is as high as $60 \%$. However, nearly $80 \%$ of patients develop progressive or alternating (recurrence and remission) forms of TA. It is therefore necessary to combine GC with conventional disease-modifying antirheumatic drugs (DMARDs), such as cyclophosphamide (CYC), methotrexate (MTX), mycophenolate mofetil (MMF), and leflunomide (LEF), to prolong remission and to taper GC $[5,6]$. The clinical manifestations of TA can be divided into the prodromal or prevasculitic phase, which is characterized by nonspecific systemic symptoms, and the stenosis phase, in which patients may present with protean symptoms of ischemia of the organs supplied by the involved arteries $[7,8]$. 
Renal-artery stenosis is the basis of ischemic nephropathy and is associated with renovascular hypertension. Renal complication of TA is characterized by renal ischemia resulting from renal artery involvement (RAI) [9, 10]. However, due to the rarity of the disease, very few studies have focused on RAI in TA patients. Thus, except for hypertension, little is known about the clinical characteristics of RAI in TA patients. This case report will give the reader an overview of Takayasu's arteritis with renovascular dysfunction.

\section{Case Report}

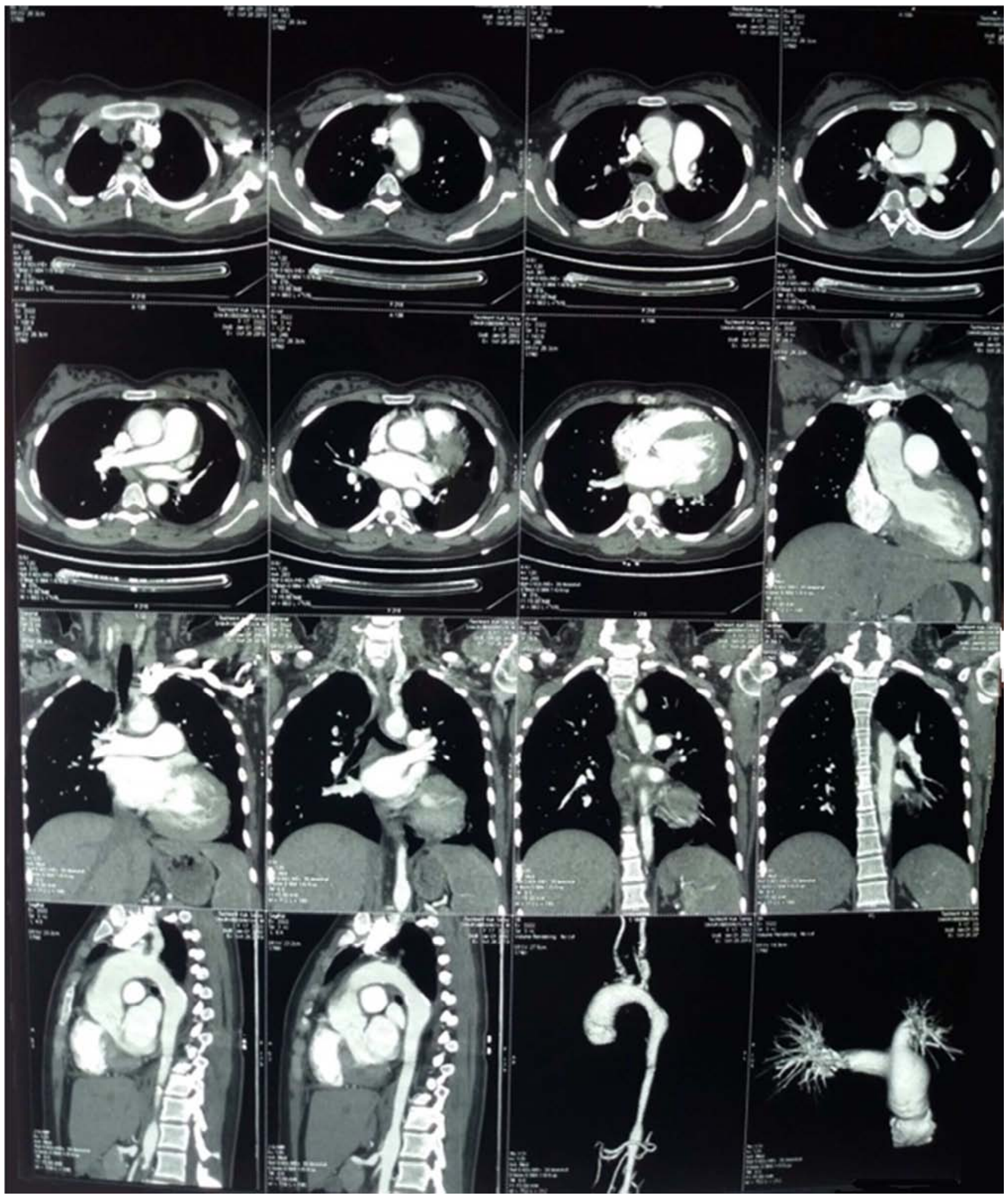

Figure 1. Multi-slice CT of thoracic and abdominal aorta. 


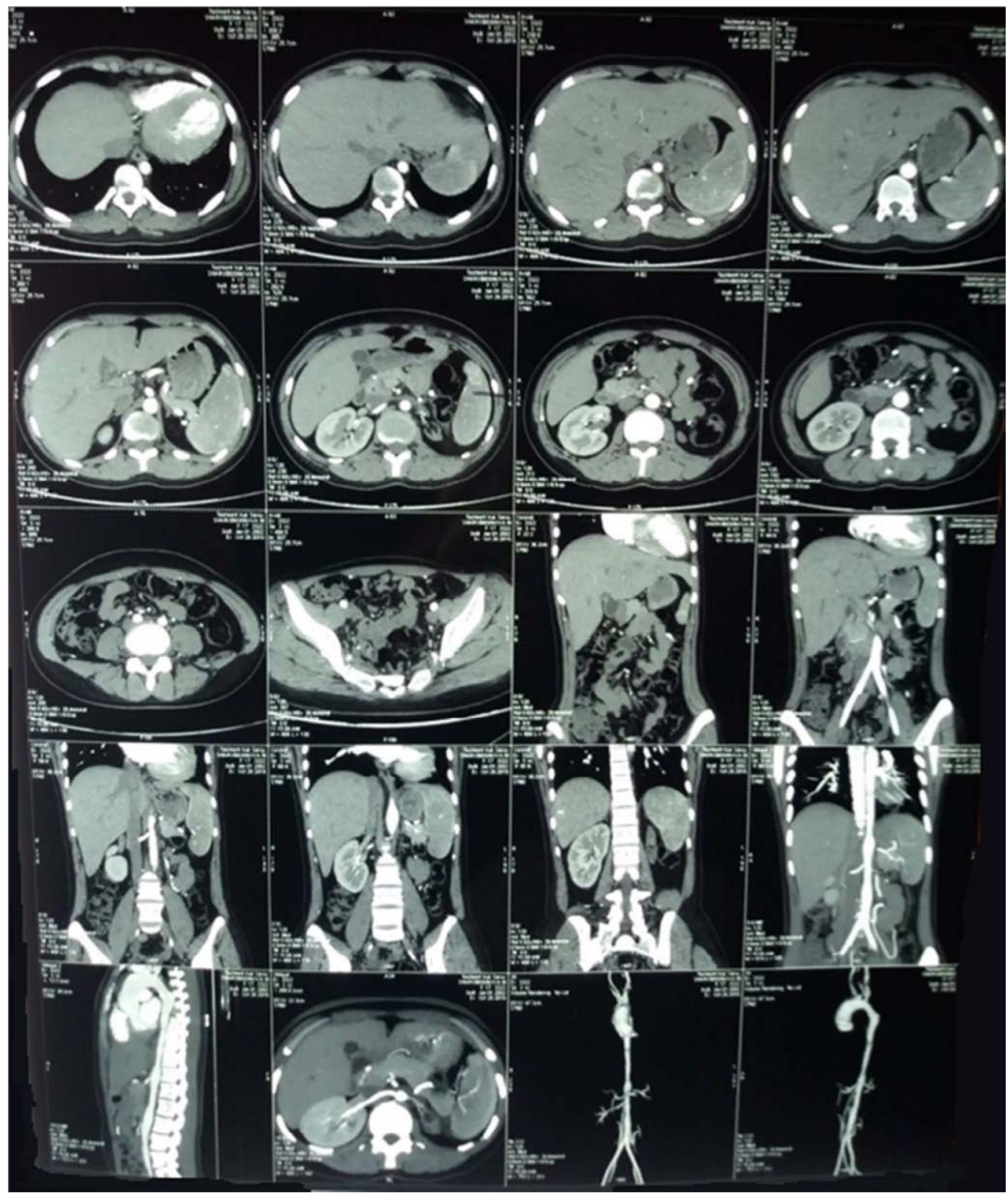

Figure 2. Multi-slice CT of thoracic and abdominal aorta.

Table 1. Clinical characteristics and laboratory findings (1st and 10th day) of patient.

\begin{tabular}{lll}
\hline Day & $\mathbf{1}^{\text {st }}$ day & $\mathbf{1 0}^{\text {th }}$ day \\
\hline Female's age (year) & 17 \\
Age at disease onset (year) & 13 \\
Number of admissions & 6 & \\
\hline
\end{tabular}




\begin{tabular}{|c|c|c|}
\hline Day & $1^{\text {st }}$ day & $10^{\text {th }}$ day \\
\hline \multicolumn{3}{|l|}{ Constitutional symptoms } \\
\hline Fever & 37,5 & 36,5 \\
\hline Malaise & + & +- \\
\hline Weight loss & $48 \mathrm{~kg}$ & $49 \mathrm{~kg}$ \\
\hline Night sweats & + & +- \\
\hline Arthralgia in knees, shoulders, hands & + & +- \\
\hline Movement-induced muscular pain in one or more limbs & + & +- \\
\hline \multicolumn{3}{|l|}{ Neurological symptoms } \\
\hline Headache & + & +- \\
\hline Ischemic stroke & + & +- \\
\hline Disparity in blood pressure between arms & $>20 \mathrm{~mm} . \mathrm{Hg}$ & $>10 \mathrm{~mm} . \mathrm{Hg}$ \\
\hline Bruit over subclavian artery or abdominal aorta & + & +- \\
\hline Syncope & +- & - \\
\hline \multicolumn{3}{|l|}{ Vascular findings } \\
\hline Bilateral carotid bruits & + & +- \\
\hline Raynaud phenomenon & + & +- \\
\hline Upper limb claudication & + & - \\
\hline Lower limb claudication & + & - \\
\hline Pulse deficit & + & + \\
\hline Asymmetric blood pressure & + & +- \\
\hline Poor peripheral pulses & + & +- \\
\hline Limb ischemia & + & +- \\
\hline Hypertension & + & +- \\
\hline \multicolumn{3}{|l|}{ Fundoscope findings } \\
\hline Takayasu's retinopathy & + & + \\
\hline \multicolumn{3}{|l|}{ Skin manifestations } \\
\hline Erythema nodosum & + & - \\
\hline Urticaria & - & - \\
\hline \multicolumn{3}{|l|}{ Laboratory data } \\
\hline \multicolumn{3}{|l|}{ Blood analysis } \\
\hline Hematocrit & $33.2 \%$ & $46.8 \%$ \\
\hline $\mathrm{WBC}\left(\times 10^{9} / 1\right)$ & $12.0 \%$ & $9.03 \%$ \\
\hline $\mathrm{RBC}\left(\mathrm{x} 10^{12} / \mathrm{L}\right)$ & $3.1 \%$ & $4.5 \%$ \\
\hline Platelet count (/mm3) & 415.000 & 352.000 \\
\hline $\mathrm{Hb}(\mathrm{g} / \mathrm{dL})$ & 10.2 & 11.2 \\
\hline ESR $(\mathrm{mm} / \mathrm{hr})$ & 46.3 & 16.2 \\
\hline C-reactive protein $(\mathrm{mg} / \mathrm{dL})$ & 36.8 & 16.25 \\
\hline $\operatorname{ALT}(\mathrm{U} / \mathrm{L})$ & 46.6 & 20.2 \\
\hline $\operatorname{AST}(\mathrm{U} / \mathrm{L})$ & 56.2 & 15.2 \\
\hline Bilirubin (total) (mg/dL) & 3.5 & 1.0 \\
\hline Bilirubin (direct) (mg/dL) & 1.2 & 0.3 \\
\hline Creatinine (mg/dL) & 7.2 & 1.2 \\
\hline Urea $(\mathrm{mg} / \mathrm{dL})$ & 156.2 & 18.1 \\
\hline $\mathrm{TC}(\mathrm{mmol} / \mathrm{l})$ & 5.02 & 4.48 \\
\hline $\mathrm{TG}(\mathrm{mmol} / \mathrm{l})$ & 1.31 & 1.21 \\
\hline $\operatorname{HDL}(\mathrm{mmol} / \mathrm{l})$ & 1.42 & 1.35 \\
\hline $\mathrm{LDL}(\mathrm{mmol} / \mathrm{l})$ & 2.72 & 2.48 \\
\hline \multicolumn{3}{|l|}{ Urine analysis } \\
\hline Urine output (ml/day) & $<500$ & $>1000$ \\
\hline Creatinine (urine) $(\mathrm{mL} / \mathrm{min})$ & 148.2 & 88.2 \\
\hline eGFR $\left(\mathrm{ml} / \mathrm{min} / 1.73 \mathrm{~m}^{2}\right)$ & 60 & 90 \\
\hline Proteins total & $>200 \mathrm{mg} / 24 \mathrm{~h}$ & $<150 \mathrm{mg} / 24 \mathrm{~h}$ \\
\hline
\end{tabular}

WBC, white blood cells; RBC, red blood cells; ESR, erythrocyte sedimentation rate; ALT, Alanine aminotransferase; AST, Aspartate aminotransferase; TC, total cholesterol; TG, triglyceride; HDL, high density lipoprotein; LDL, low density lipoprotein; eGFR, estimated glomerular filtration rate. 


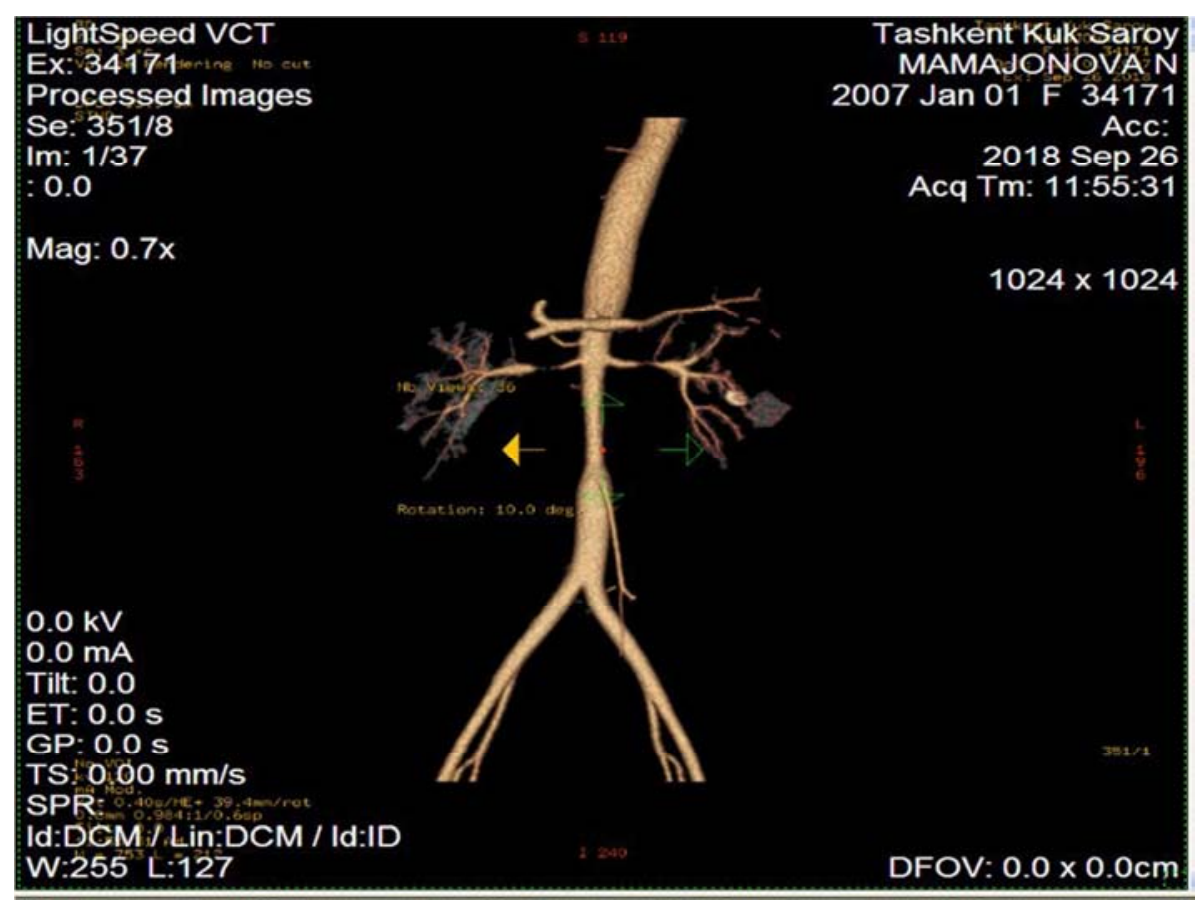

Figure 3. Multi-slice CT with contrasting the thoracic and abdominal aorta.

Multi-slice CT with contrasting the thoracic and abdominal aorta: Atherosclerosis of the thoracic and abdominal aorta and its branches. Occlusion of the left common carotid artery (CCA), the right subclavian artery. Stenosis of the thoracic and abdominal aorta, left subclavian artery, celiac trunk, superior mesenteric artery, both renal arteries. Vascular changes are more consistent with the consequences of aortoarteritis. Expansion of the pulmonary trunk. Hypoplasia of the left kidney.

Table 2. Size of the thoracic arteries

\begin{tabular}{ll}
\hline Arteries & $\begin{array}{l}\text { Diameter } \\
\text { (mm) }\end{array}$ \\
\hline Ascending part of the thoracic aorta & 32,0 \\
Aortic ach & 25,0 \\
Upper third of the descending part of the thoracic aorta & 14,0 \\
Middle third of the descending part of the thoracic aorta & 19,0 \\
Lower third of the descending part of the thoracic aorta & 10,0 \\
Pulmonary trunk & 35,0 \\
Right pulmonary artery & 18,0 \\
Left pulmonary artery & 16,0 \\
\hline
\end{tabular}

Table 3. Size of the abdominal and renal arteries.

\begin{tabular}{ll}
\hline Arteries & Diameter $(\mathbf{m m})$ \\
\hline Initial part of the aorta & 9,0 \\
Upper third part of the aorta & 15,0 \\
Middle third part of the aorta & 10,0 \\
Lower third part of the aorta & 14,0 \\
Celiac trunk & 8,0 \\
Upper mesenteric artery & 4,0 \\
Right renal artery & 5,0 \\
Left renal artery & 2,0 \\
Lower mesenteric artery & 6,0 \\
\hline
\end{tabular}

The walls of the thoracic aorta and its branches are uneven, clear. The clearance of the right common carotid artery upper third is preserved, the walls are uneven. The lumen of the left common carotid artery is not contrasted (on the scans examined), the walls with the presence of calcification sites. The lumen of the right subclavian artery and the initial third part is preserved, then the artery does not contrast, departs from the right wall of the aortic arch, after the left subclavian artery leaves, passes behind the esophagus and trachea. Clearance of the celiac trunk at aortic orifice is narrowed by $50 \%$. Common hepatic and splenic arteries without features. The lumen of the right renal artery in the proximal and distal third is narrowed by $35 \%$. The clearance of the left renal artery in the mouth is narrowed by $50 \%$. The left kidney is reduced in size $5.7 *$ $1.7 \mathrm{~cm}$.

Conclusion: MSCT - signs of atypical discharge of the right subclavian artery from the posterior surface of the aortic arch with the presence of extended sections of occlusion in upper third and lower third. Atypical discharge of the common carotid artery on the right with a single trunk with a common carotid artery on the left. Occlusion with upper third subclavian artery on the left. Occlusion of the common carotid artery on the left along the entire length with the presence of a pronounced collateral network that communicates with the bed of the subclavian and vertebral arteries on the left. Ectasia of the ascending aorta, the trunk of the pulmonary artery, lower third of the subclavian and vertebral arteries on the left throughout. Occlusion lower third of the external carotid artery on the right. Single stenoses of extracranial arteries, the largest of which (57\%) is located in lower third of the common carotid artery on the right. Hypoplasia of the left internal carotid artery.

Echocardiography: the left ventricle is dilated. ECG: sinus 
tachyarrhythmia. Heart rate $-80-100 / \mathrm{min}$. The electric axis is not deflected. Subendocardial hypertrophy and ischemia of the lateral and posterior walls of the left ventricle. A tuberculin test was normal. Optometrist - mild myopia Chest $\mathrm{x}$-ray - expansion of the roots of the right lung. The sinuses are free, the heart is normal.

The radiological results corresponded with the finding of a consistent difference in the blood pressure of about 20 $\mathrm{mmHg}$ between the left and right upper arm.

Duplex ultrasonography of the left renal artery suggested severe stenosis.

Selective angiography showed stenosis of aortic arch, proximal great vessels and renal artery.

Biopsy of the left renal artery: granulomatous thickening of renal artery; plasma cells and lymphocytes in media and adventitia; vascular fibrosis.

\section{Follow-up and Treatment at the Department of Rheumatology}

Corticosteroids (methylprednisolone $750 \mathrm{mg}$ once daily over three days followed by oral prednisolone $1 \mathrm{mg} / \mathrm{kg}$ daily); subcutaneous methotrexate $20 \mathrm{mg}$ once weekly administered. Surgical intervention (e.g., bypass) have done in critical stenosis of the affected vessels, such as subclavian, internal carotid and renal artery during the 3 years. Antihypertensive treatment. Further tapering of oral prednisolone is scheduled and follow-up at the Department of Rheumatology.

Treatment response was defined according to four criteria $[11,12]$ : (a) no new/worse systemic symptoms; (b) no new/worse vascular signs or symptoms; (c) normal ESR and CRP levels (ESR $40 \mathrm{~mm} / \mathrm{H}, \mathrm{CRP} 10 \mathrm{mg} / \mathrm{L}$ ); and (d) GC dosage $15 \mathrm{mg} / \mathrm{d}$ throughout the induction treatment. Complete remission (CR) was defined as fulfilment of all the four criteria. Partial remission (PR) was defined as satisfying criterion (b) plus at least one of the other three criteria. CR and PR were collectively defined as response rate (RR). If CYC was judged failure in induction, the regimen was switched to a combined regimen of GC and LEF. Radiological progress was defined as new lesions or vessel wall progression $25 \%$ including vascular stenosis and/or thickening from MRA imaging. Radiological improvement in MRA was defined as an increase $25 \%$ of the lumen of the original lesion. All of the MRA angiograms were read in a blinded manner by two radiologists who were not aware of the treatment regimen.

\section{Discussion}

This patient had an acute renal failure due to renal-artery stenosis and left sided renal hypoplasia. The clinical finding of non-palpable radial artery pulses together with the histological finding of inflammation suggested the presence of systemic vasculitis. Laboratory findings are not specific to Takayasu's disease. The diagnosis is based on the presence of three of the six clinical criteria set forth by the American
College of Rheumatology:

a. The patient's age being younger than 40 years at the onset.

b. Claudication of the extremities.

c. A decreased brachial artery pulse.

d. A systolic blood pressure difference between the arms $>$ $10 \mathrm{mmHg}$.

e. A murmur over the subclavian arteries or aorta.

f. Abnormal arteriographical findings [13-15].

We diagnosed Takayasu's disease in this patient based on the clinical picture and the findings of the multi-slice CT, angiography and biopsy of the affected artery. Kidney involvement in the form of unilateral kidney hypoplasia is most important, and is rarely described in the literature. Urinary-tract obstruction was ruled out on ultrasonography, and a normal urine sediment made the diagnosis of acute glomerulonephritis unlikely. Renal artery stenosis as a manifestation of systemic vasculitis is rare. However, some clinical, parameters such as pulseless extremities, joint pain, generalized malaise, weak radial and pedal pulses, disparity in blood pressure between extremities, bruit over aortal branches, hypertension may indicate Takayasu's arteritis and warrant further diagnostic procedures. Renal artery stenosis in Takayasu's arteritis should be considered as a cause of low eGFR, oliguria, proteinuria with an excellent prognosis when revascularization is initiated early.

\section{Conclusion}

In this patient was stabile arterial hypertension due to renovascular damage. The significantly decreased glomerular filtration rate (eGFR) under $90 \mathrm{~mL} / \mathrm{min} / 1.73 \mathrm{~m}^{2}$ risk factor for renal dysfunction among patients with Takayasu's arteritis. The eGFR is correlated negatively with the severity of renal artery stenosis. After surgical intervention of renal artery eGFR increased for more than $15 \%$ and level of arterial hypertension was decreased. In conclusion, TA has significant adverse effects on RA, especially if not diagnosed and timely treated properly. When they occur concomitantly, more attention and care is needed to prevent complications. Angioplasty, stent implantation, and bypass surgery can successfully salvage renal mass and function. Patients with renal-artery stenosis should be screened for systemic vasculitis, such as Takayasu's arteritis.

\section{Funding}

This research did not receive any specific grant from funding agencies in the public, commercial, or not-for-profit sectors.

\section{Declaration of Competing Interest}

The authors declare that they have no known competing financial interests or personal relationships that could have appeared to influence the work reported in this paper. 


\section{References}

[1] Skeik N, Rodriguez A, Engstrom B. Rare case of Takayasu arteritis with concurrent aneurysmal dilation and stenosis. Int J Angiol 2015; 24: 244-8. https: //doi.org/ 10.1055/s-00351549363 .

[2] Skeik N, Ostertag-Hill CA, Garberich RF, Alden PB, Alexander JQ, Cragg AH, et al. Diagnosis, management, and outcome of aortitis at a single center. Vasc Endovasc Surg 2017; 51: 470-9. https: //doi.org/10.1177/1538574417704296.

[3] Kerr GS, Hallahan CW, Giordano J, Leavitt RY, Fauci AS, Rottem M, et al. Takayasu arteritis. Ann Intern Med 1994; 120: 919-29. https: //doi.org/10.7326/0003-4819- 120- 11199406010-00004.

[4] Alibaz-Oner, F. and Direskeneli, H. Update on Takayasu's arteritis. Presse Med. 2015; 44: e259-e265.

[5] Maritati, F., Iannuzzella, F., Pavia, M. P. et al. Kidney involvement in medium- and large-vessel vasculitis. J Nephrol. 2016; 29: 495-505. doi: 10.1007/s40620-016-0303-8.

[6] Sun Y, Ma L, Chen H, Kong X, Lv P, Dai X, et al. Analysis of predictive factors for treatment resistance and disease relapse in Takayasu's arteritis. Clin Rheumatol 2018; 37: 2789-95. doi: 10.1007/s10067-018-4094-2.

[7] Arend WP, Michel BA, Bloch DA, et al. The American College of Rheumatology 1990 criteria for the classification of Takayasu arteritis. Arthritis Rheum. 1990; 33: 1129-34. doi: 10.1002/art.1780330811.

[8] Sueyoshi E, Sakamoto I, Hayashi K. Aortic aneurysms in patients with Takayasu's arteritis: CT evaluation. AJR Am J Roentgenol. 2000; 175 (6): 1727-1733.

[9] Song M H, Nakayama T, Hattori K, Tokuda Y, Mabuchi Y, Ueda Y. Aortic root aneurysm in Takayasu arteritis syndrome: exploration in active phase and repair in inactive phase. $\mathrm{J}$ Thorac Cardiovasc Surg. 2008; 136 (4): 1084-1085.

[10] Geraldes R, Batista P, Pedro L M, Fernandes A, Melo T P. Takayasu arteritis presenting with internal carotid artery dissection. Cerebrovasc Dis. 2012; 33 (4): 408-409.

[11] Tabata M, Kitagawa T, Saito T. et al. Extracranial carotid aneurysm in Takayasu's arteritis. J Vasc Surg. 2001; 34 (4): 739-742.

[12] Hoyer B F, Mumtaz I M, Loddenkemper K. et al. Takayasu arteritis is characterised by disturbances of $\mathrm{B}$ cell homeostasis and responds to B cell depletion therapy with rituximab. Ann Rheum Dis. 2012; 71 (1): 75-79.

[13] Clifford A., Hoffman G. S. Recent advances in the medical management of Takayasu arteritis: an update on use of biologic therapies Curr Opin Rheumatol 2014; 26: 7-15.

[14] Grayson P. C., and al. Association of vascular physical examination findings and arteriographic lesions in large vessel vasculitis $J$ Rheumatol 2012; 39: 303-309.

[15] Ham SW, Kumar SR, Rowe VL, Weaver FA. Disease progression after initial surgical intervention for Takayasu arteritis. J Vasc Surg. 2011; 54: 1345-1351. 